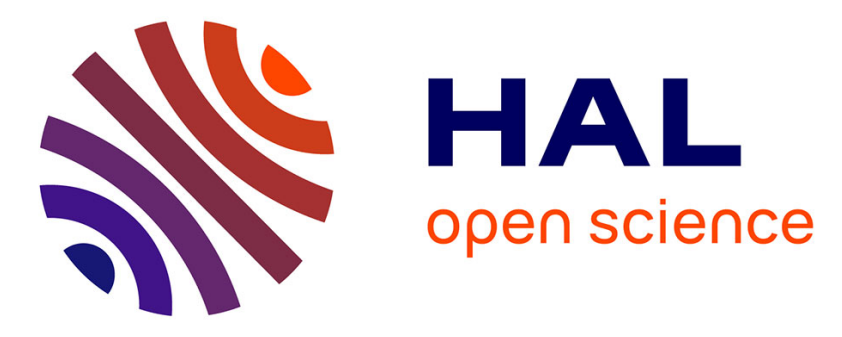

\title{
Wavelength scaling of THz emissions by two-color filaments in air
}

\author{
L. Bergé, A. Nguyen, K. J Kaltenecker, J. C Delagnes, B. Zhou, E. Cormier, \\ N. Fedorov, R. Bouillaud, D. Descamps, I. Thiele, et al.
}

\section{- To cite this version:}

L. Bergé, A. Nguyen, K. J Kaltenecker, J. C Delagnes, B. Zhou, et al.. Wavelength scaling of THz emissions by two-color filaments in air. 2019 Conference on Lasers and Electro-Optics Europe \& European Quantum Electronics Conference (CLEO/Europe-EQEC), Jun 2019, Munich, Germany. pp.1-1, 10.1109/CLEOE-EQEC.2019.8872607 . hal-02327608

\section{HAL Id: hal-02327608 \\ https://hal.science/hal-02327608}

Submitted on 22 Oct 2019

HAL is a multi-disciplinary open access archive for the deposit and dissemination of scientific research documents, whether they are published or not. The documents may come from teaching and research institutions in France or abroad, or from public or private research centers.
L'archive ouverte pluridisciplinaire HAL, est destinée au dépôt et à la diffusion de documents scientifiques de niveau recherche, publiés ou non, émanant des établissements d'enseignement et de recherche français ou étrangers, des laboratoires publics ou privés. 


\title{
Wavelength scaling of THz emissions by two-color filaments in air
}

\author{
$\underline{\text { L. Bergé }}^{1}$, A. Nguyen ${ }^{1}$, K. J. Kaltenecker ${ }^{2}$, J. C. Delagnes ${ }^{3}$, B. Zhou ${ }^{2}$, E. Cormier ${ }^{3}$, N. Fedorov ${ }^{3}$, R. \\ Bouillaud $^{3}$, D. Descamps ${ }^{3}$, I. Thiele ${ }^{4}$, S. Skupin ${ }^{5}$, and P. U. Jepsen ${ }^{2}$ \\ 1. CEA-DAM, DIF, 91297 Arpajon, France \\ 2. DTU Fotonik, Department of Photonics Engineering, Technical University of Denmark, DK-2800 Kongens Lyngby, Denmark \\ 3. Univ. Bordeaux - CNRS - CEA, Centre Lasers Intenses et Applications, UMR 5107, 33405 Talence, France \\ 4. Department of Physics, Chalmers University of Technology, SE-412 96 Göteborg, Sweden \\ 5. Institut Lumière Matière, UMR 5306 Université Lyon 1 - CNRS, Université de Lyon, 69622 Villeurbanne, France
}

Producing terahertz $(\mathrm{THz})$ radiation by ultrashort laser pulses has become an active field of research because of its promising applications in, e.g., spectroscopy and medical imaging [1]. Efficient $\mathrm{THz}$ emitters can be obtained by focusing into air a two-color femtosecond light pulse, composed of fundamental (FH) and second (SH) harmonics, in order to create a plasma channel that acts as a frequency converter [2]. Recent studies [3,4] showed that increasing the pump wavelength enhances the THz energy. However, there is no consensus on the gain factors expected when pushing the FH wavelength, $\lambda_{0}$, from the near-IR to the mid-IR range. Clerici et al. [3] reported THz energy yields scaling like $\lambda_{0}^{4.6}$ in the range $0.8-1.8 \mu \mathrm{m}$. By contrast, according to the local-current model $[2,4]$, the largest THz energy attained by two colors with $\pi / 2$ relative phase should follow a scaling in $\lambda_{0}^{2}$ only.

Here we address this apparent contradiction by performing two distinct experiments scanning the wavelength range $1.2-2.6 \mu \mathrm{m}$. The experimental campaigns used two different OPA systems (TOPAS). Figure 1(a) summarizes the THz signals recorded with a pyroelectric detector. Despite the different wavelength ranges investigated, the fitting curves of this figure underline impressive growths in $\lambda_{0}^{\alpha}$ with powers $\alpha$ not only exceeding $\sim 4.6$ [3], but also reaching up to almost 15 in the highest wavelength ranges. We also observe a decrease in the pyroelectric signal beyond specific $\lambda_{0}$ values, which may indicate some optimum wavelengths where maximum THz generation is achieved. Such a behavior is present in the data points of Ref. [3] as well, recalled by the gray symbols and line.
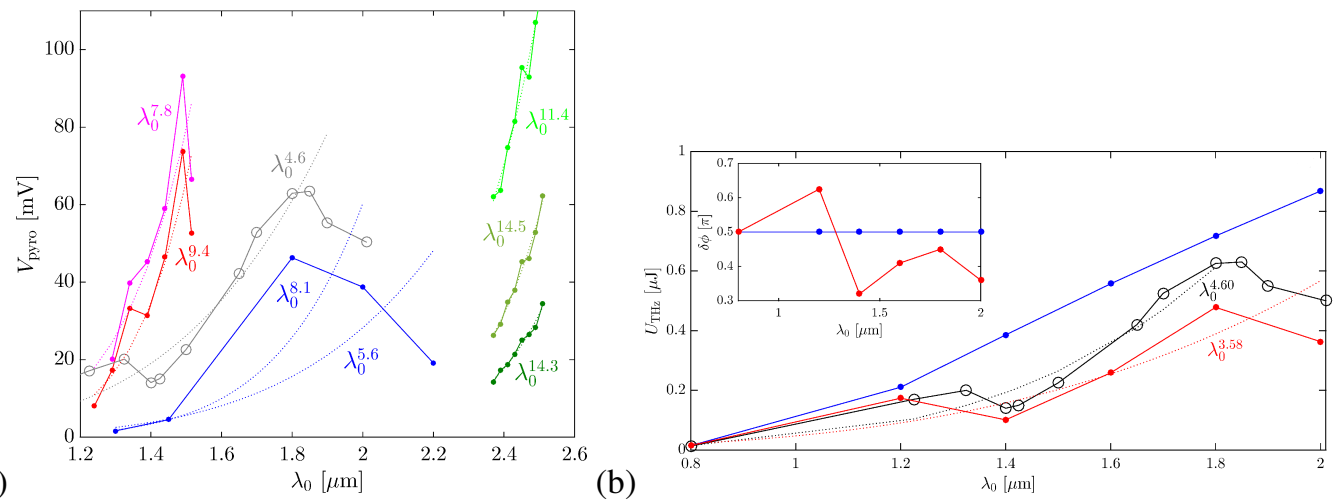

Figure 1 (a) Pyroelectric detector signals vs FH wavelength in the frequency window $v<20 \mathrm{THz}$ for the two experimental campaigns. The average input power of the pump beam is constant for each curve, namely, $720-840 \mathrm{~mW}$ (red), $300 \mathrm{~mW}$ (blue), 348-420-558 $\mathrm{mW}$ (green curves). Dotted curves are fitting curves in $\lambda^{\alpha}$. Gray circles recall the data of Ref. [3]. (b) THz energy yield computed with the 3D UPPE model (red dots) for the experimental data of [3] (black circles) with the initial phase shifts specified in inset. The blue curve is associated to $\pi / 2$ phase angle at the exit of the doubling crystal.

Here we show that such impressive growths can be explained by changes in the laser parameters as the FH wavelength is increased. Comprehensive 3D simulations combining both computations of the SH/FH energy ratio from the doubling crystal and a unidirectional numerical solver [6] are performed using the experimental values of the beam diameters and pulse durations. They reproduce reasonably well the behaviors of $\mathrm{THz}$ energies reported from the experiments, that is, not only a global growth in $\sim \lambda_{0}^{\alpha}$, but also the occurrence of optimum FH wavelengths beyond which efficiency in THz generation drops [Fig. 1(b)]. We demonstrate that the latter effect strongly depends on the phase angle between the two colors exiting the crystal, which varies with $\lambda_{0}$ for a fixed distance separating the plasma zone from the doubling crystal. In particular, drops in the THz signal around specific wavelengths $\left(\lambda_{0}=1.4\right.$ and $\left.2.0 \mu \mathrm{m}\right)$ are due to variations in the relative phase. A constant phase angle of $\pi / 2$ at the crystal exit renders the THz energy increase monotonous (blue curve).

\section{References}

[1] M. Tonouchi, "Cutting-edge terahertz technology," Nat. Photon. 1, 97 (2007).

[2] K. Y. Kim et al., "Coherent control of terahertz supercontinuum generation in ultrafast laser-gas interactions," Nat. Photon. 2, 605 (2008).

[3] M. Clerici et al., "Wavelength scaling of terahertz generation by gas ionization," Phys. Rev. Lett. 110, 253901 (2013).

[4] A. Nguyen et al., "Spectral dynamics of THz pulses generated by two-color laser filaments in air," Opt. Express 25, 4720 (2017).

[5] N. S. Makarov et al., "Two-photon absorption standards in the 550-1600 nm excitation wavelength range," Opt. Express 16, 4029 (2008).

[6] M. Kolesik and J. V. Moloney, "Nonlinear optical pulse propagation simulation," Phys. Rev. E 70, 036604 (2004). 